\title{
METALLOGRAPHY OF NON-METALLIC INCLUSIONS IN PIPE METAL AND IMPACT ASSESSMENT OF DEFECT STRUCTURES ON NON-DESTRUCTIVE TESTING OUTCOMES
}

\author{
D. V. Zhukov ${ }^{1,2}$, S. V. Konovalov' ${ }^{1}$ A. A. Melnikov ${ }^{3}$, Danhe Chen ${ }^{1}$ \\ ${ }^{1}$ Nanjing University of Science and Technology (Nanjing, China) \\ ${ }^{2}$ Gazprom Transgaz Samara LLC (Samara, Russia); \\ ${ }^{3}$ Samara National Research University (Samara, Russia);
}

E-mail: dzetlab@yandex.ru; ksv@ssau.ru; melnickov.alex@yandex.ru; juliachen@njust.edu.cn

\section{AUTHOR'S INFO}

D. V. Zhukov, Head of the Database Maintenance Group of the Equipment and Facilities Diagnostics Service, Post Graduate of Samara National Research University,

S. V. Konovalov*, Dr. Eng., Prof., Head of Dept. of Materials Technology and Aviation Material Science A. A. Melnikov, Cand. Eng., Associate Prof., Dept. of Materials Technology and Aviation Material Science Danhe Chen, Dr. Eng., Prof., School of Mechanical Engineering

*Corresponding author: S. V. Konovalov, Dr. Eng., Prof

Key words:

inclusions, lamination, metallurgical defect, ultrasonic thickness measurement, natural gas pipeline.

\begin{abstract}
A B S T R A C T
Low carbon steel pipes represent a core component in the gas pipeline system, so it is necessary to improve constantly diagnostic operations and assessment methods of their technical state. Studies on objects operated in diverse conditions within a long period provide reliable data on the real behavior of materials.

A key issue is the investigation of characteristics and behavior of products with primarily incorporated defective structures undetected while manufacturing and constructing. It is difficult to forecast the behavior of such defects, in addition, considerably more work need to be done to determine their development, detection methods, and more importantly, their hazards.

The reported study investigates the phases, structure and sizes of inclusions detected in the defective pipe metal in the natural gas pipeline. The property that characterizes defects of interest is their concentration within one pipe section in combination with diverse thickness, composition, and location in the pipe wall. Defects are found at various depths, forming one, two and more layers. The difference in structure and phase composition is outlined. The research has pointed out principal inclusions represent fragments of charge materials - fluorite and broken fireclay brick, a number of defects result from casting defects, e.g. gas bubbles and shrinkage holes. Non-destructive ultrasonic testing is implemented; the importance of thickness and structure of inclusions for measurement data has been realized.
\end{abstract}

\section{Introduction}

The EGIG statistics [1] says a number of gas line destructions caused by deficient materials and constructions has been gradually declining in Western Europe, nevertheless, their percentage in a total number of failures is $17.79 \%$ so far. A number of incidents for this reason are reported to become less frequent due to several factors, principally, thanks to the advancement of rolled metal manufacturing technologies and quality improvement of diagnostics works. Although there is no comprehensive publicly available statistical data on failures and incidents in gas lines in the Russian Federation, a length of gas lines taken into account by EGIG is approximately 142 thousand kilometers [1] and more than 172 thousand kilometers of gas pipelines [2] is operated by PAO «Gazprom», so a risk of structural damages in constructions caused by the defective material structure is still high. Therefore, it is necessary to detect defects timely and assess them appropriately to reveal any possible hazards. The assessment of defects is to focus on instances when pipeline sections non-hazardous for the normal use are replaced unreasonably or taken out of service for repair and on keeping safe and healthy the work environment. The regular implementation of such inspection is supposed to be a principal measure to ensure the reliability of natural gas pipelines [3].
The difference in materials characteristics operated for a long time is reported [4-6]; the most important outcome to emerge from the research is the significantly decreasing impact toughness considered as a factor of structural ageing. A vast body of literature has investigated the influence of the corrosion on gas pipeline metal [7-8] and the development of stress-corrosion defects [10-12]. A number of studies [13-15] have highlighted the role of indentations, inter alia with diverse defects on them.

For instance, an indistinctive manufacturing defect (the overlap type) undetected while manufacturing and developed to a considerable extent over 20 years of operation is reported [16]. The testing has revealed a defect section of interest was cut out of a gas line in operation, however, several more precise studies and laboratory research have highlighted it was unnecessary to replace it and disclosed reasons for the faulty findings when diagnosing.

It has been up till now one of the most critical challenges to detect and assess properly a hazard level of planar defects inside the pipeline steel, e.g. segregation-type inclusions [17] and lamination of different origin [18, 19], e.g. rolled slag inclusions and gas bubbles. Liquation represents a quite frequently occurring type of metallurgical defects and refers [20] to local assemblages of chemical elements and their compounds resulting from the solidification while cooling. Lamination is defined [21] to be a 
defect forming as a separation gap in inner layers of the metal without breaking its surface. Ultrasonic automated control methods of laminations and acceptance standards are specified in [22] and [23]. In gas main pipelines laminations found everywhere except for pipe ends, bringing no damage to the surface and extending less than $80 \mathrm{~mm}$ in any direction are accepted to be admissible, furthermore, their total area is to be below $5000 \mathrm{~mm}^{2}$. At the same time no regulations are stated for dimensions of liquation defects. The difference between liquation and moderate-size laminations is quite conditional and is not distinct when diagnosing with regular methods.

This study aims to research the element and phase composition of planar inclusions in a pipe metal, and implement the fractography of laminated surfaces. Of particular concern is to find a reason pipes with numerous defects of the lamination-type are allowable for operation. In addition, the role of the structure and thickness of a layer containing inclusions for findings of ultrasonic testing is to be assessed.

\section{Materials and Methods of Research}

\subsection{Object of research}

For the purpose of research a defective pipe section (diameter - $325 \mathrm{~mm}$, nominal wall thickness $-7 \mathrm{~mm}$, operated under pressure $7.5 \mathrm{MPa}$ ) preliminary cut from a gas pipeline was used. The gas pipeline was commissioned in 1995. The structure represents a single-joint welded pipe [24] manufactured of low carbon grade 20 steel [25]; such pipes are broadly used for gas pipeline systems. The spectroscopy was carried out using an optical emission spectrometer PMI-Master UVR-PRO (WASAG, Germany) to determine a grade of steel, the exact concentration of impurities and alloying elements, as well as to check the compliance of a pipe material with the documentation submitted by the manufacturer.

30 samples (180-200 x14-20 mm) were cut out from numerous defective sections on a pipe for laboratory tests, as well as 3 samples from defect free sections.

\subsection{Fractography and macro-analysis of microsections and opened up surfaces}

A macro-analysis of a side surface in microsections was carried out as the preliminary research, in addition, the fractography of opened up surfaces was performed on samples, which were subjected to a microanalysis then. Side surfaces of samples to be analyzed were machined by a face grinder.

\subsection{Optical microscopy}

Once the fractography and macro-analysis had been conducted, segments of $40 \mathrm{~mm}$ were cut of samples selected for optical and electron microscopy. Microsections were prepared using materials for sample preparation Aka-Clear (Akasel A/S, Denmark) and processed by a metallographic grinding and polishing machine LS2+LSA (Remet, Italy). Samples were etched in $4 \%$ nital before visually inspected.

The microsections of samples were examined by the method of light optical microscopy with $100 \mathrm{x}$ to $500 \mathrm{x}$ magnification using a binocular optical metallographic inverted microscope METAM LW-31 (joint-stock company «LOMO», Russia).

\subsection{Research into morphology and structural heterogeneity}

To analyze the structure and phase composition of samples, we used a scanning electron microscope TESCAN (Tescan, a.s., Czech Republic) tooled with a system of X-ray energy-dispersive microanalysis Oxford INCAx-act (Oxford Instruments, Great Britain), which makes it possible to investigate the material composition of components with a concentration of $0.1-0.3 \%$ to $100 \%$ in local zones (a diameter up to $3 \mu \mathrm{m}$ ) and the distribution of chemical elements in corresponding phases.

\subsection{Ultrasonic testing of samples}

The thickness of inclusions in samples of interest was measured before optical microscope testing. The bilateral ultrasonic investigation with a focus on the material integrity over defective zones was carried out by the pulse-echo technique using a variety of sensors. For the purpose of research, we used a thickness measuring device A1210 («AKS» LCC; Russia) with converters S3567 2.5A0D10CL into $2.5 \mathrm{MHz}$ with a measurements range 0.8-300 and D1771 4.0A0D12CL into $4 \mathrm{MHz}$ with a measurements range $0.7-300 \mathrm{~mm}$. These measurements were an applied part of the research and conducted to disclose the relevance of inclusion layer thickness for readings of the measuring equipment and improve the accuracy in the determining lamination parameters.

\section{Results}

\subsection{Analysis of chemical composition}

Table 1 presents data on the chemical composition of metal tested by an optical emission spectrometer PMIMaster UVR-PRO, compared with the standard requirements [23]. The composition of steel is similar to the constructional grade 20 steel.

\subsection{Macro-analysis of a side surface in samples}

When inspecting a side surface of samples, planar inclusions in a pipe wall were visible to unaided eye or under insignificant magnification (fig. 1). The thickness of the widest light yellow to green inclusion was as much as $1.0 \mathrm{~mm}$.

An interesting outcome is the varying thickness of inclusions and their position on the wall height. A number of inclusions are detected approximately along the wall axis 


\begin{tabular}{|l|c|c|c|c|c|c|c|c|c|}
\hline Table 1. Summarized data on the chemical composition \\
\hline \multirow{2}{*}{ Percentage } & \multicolumn{10}{|c|}{ A parameter to be measured } \\
\cline { 2 - 10 } & $\mathrm{C}$ & $\mathrm{Si}$ & $\mathrm{Mn}$ & $\mathrm{Cr}$ & $\mathrm{Cu}$ & $\mathrm{Al}$ & $\mathrm{Ti}$ & $\mathrm{S}$ & $\mathrm{P}$ \\
\hline Measured & 0.214 & 0.281 & 0.534 & 0.07 & 0.026 & 0.045 & 0.046 & 0.017 & 0.011 \\
\hline GOST 1050-88 & $0.17 \ldots 0.24$ & $0.17 \ldots . .0 .37$ & $0.35 \ldots . .0 .65$ & $<0.25$ & - & - & - & $<0.04$ & $<0.035$ \\
\hline
\end{tabular}
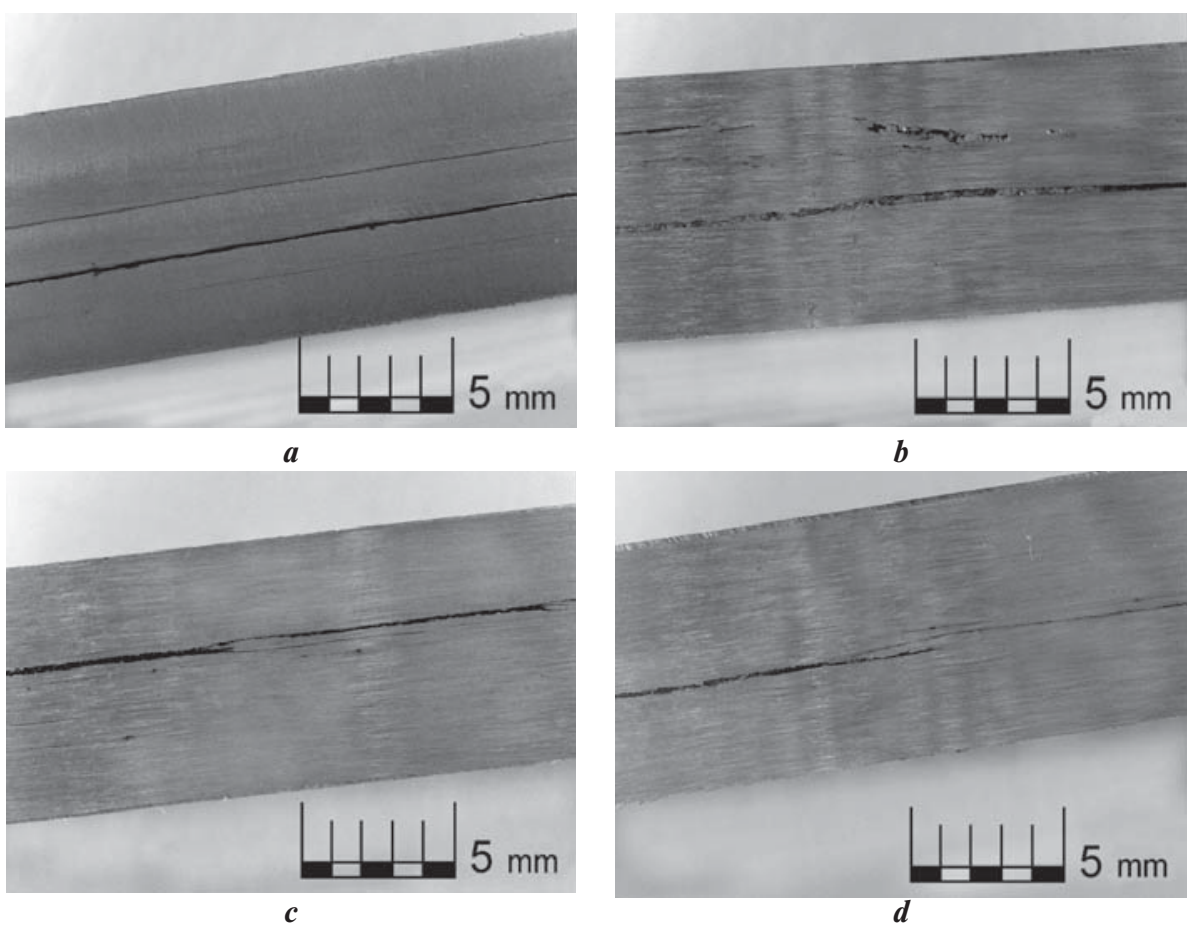

Fig. 1. A section of a pipe wall with planar inclusions of various number, position and thickness: $a-$ a zone with three extended layers of inclusions; $b-$ a zone with extended longitudinal inclusion and not-extended inclusions with a variety of forms; $c-$ a branched extended inclusion; $d-$ a branched extended inclusion with the variable thickness
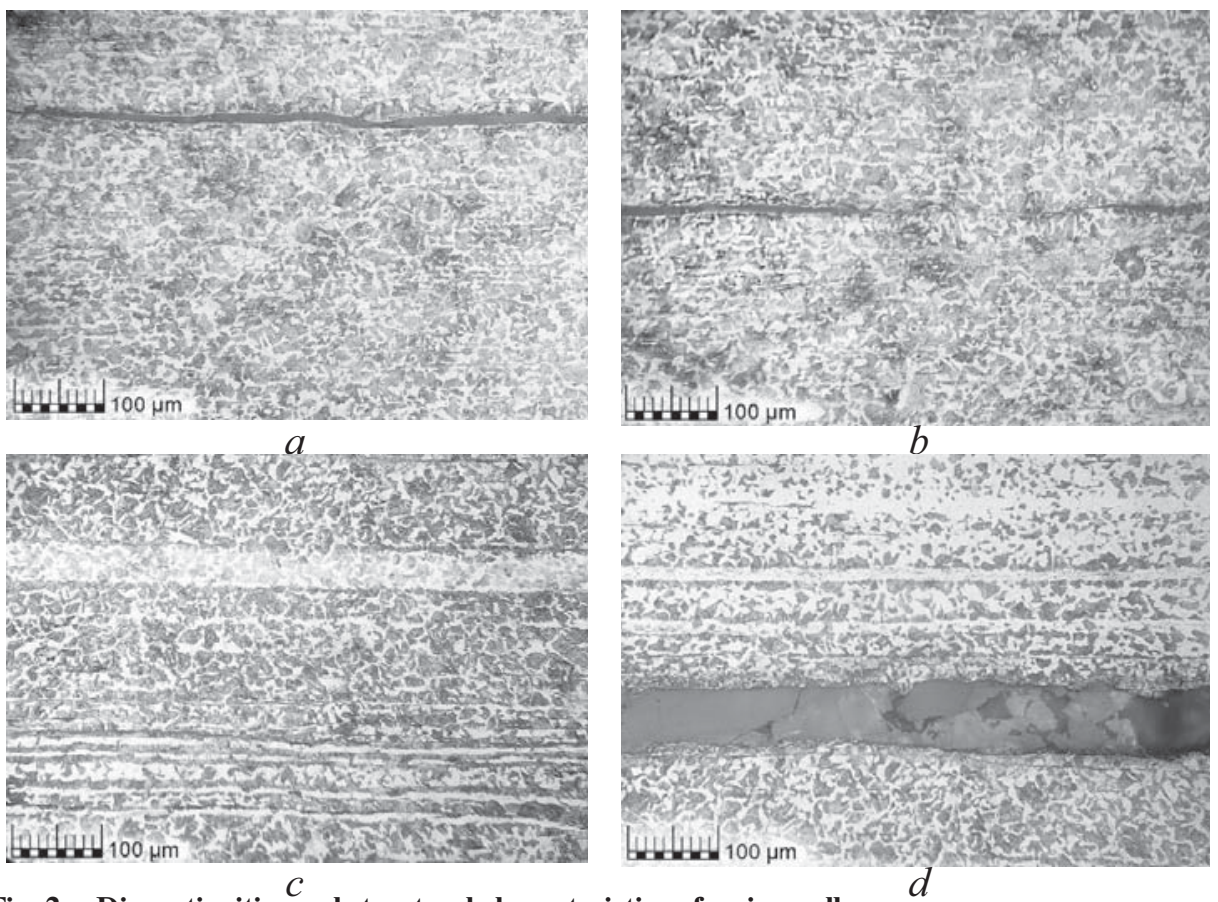

Fig. 2. Discontinuities and structural characteristics of a pipe wall:

$a$ - extended inclusions with the thickness of $10 \mu \mathrm{m} ; b-$ broken inclusions with the thickness up to $5 \mu \mathrm{m} ; c$ - layered metal structure with ferrite and pearlite layers; $d-$ extended inclusions with the thickness up to $1 \mu \mathrm{m}$ similarly to the most typical lamination pattern caused by the dendrite liquation. However, inclusions found in the majority of samples divided a pipe wall into several layers (fig. $1 a, b$ ), demonstrated other volumetric and planar defects (fig. $1 b$ ), and were displaced towards the outer (fig. $1 c$ ) or inner (fig. $1 d$ ) pipe surface. Most inclusions with parallel line-type or short planar incorporated objects (fig. 1 $b$ ) were located not on the axis of a pipe wall. Furthermore, some inclusions were branched when propagating, penetrating into another layer or forming several parallel stripes (fig. 1 $c, d)$. The gap between inclusions was in a range from 0.1 to $2 \mathrm{~mm}$. The inspection of the pipe revealed a defect zone occupies approximately $40 \%$ of the perimeter and fails to meet the requirements [22] for area, extension and cross impact of defects.

\subsection{Fractography of inner surfaces in samples}

A certain number of being analyzed samples was opened up along the inclusions plane. The visual inspection of sample surfaces has demonstrated the color, density and structure of inclusions, the base metal state under inclusions of the lamination zones are dissimilar even in different layers of same samples. A white, light yellow or green removable bloom was detected in some opened up zones. The surface of metal under the bloom demonstrated a uniform, wavy structure with imperfections extended in the direction of rolling. Secondtype lamination zones detected more frequently contained quite brittle transparent to red and yellow glassy inclusions. The surface of metal was smoothed. The third-type dull surface with hard-removable 
dark bloom was detected less frequently (2 of 30 samples). On the surface of these samples we also detected oxidizing colour zones, the variation of colors in the steel was studied in details in [26], and overheated zones in the samples of interest are local and formed when rolling. The chemical composition of inclusions was explored in $\mathrm{X}$-ray microanalysis.

\subsection{Optical microscopy of a sample side surface}

The visual inspection has provided more details of extended longitudinal cracks. Additionally, thinner discontinuity zones of a variety of lengths were detected in the base metal.
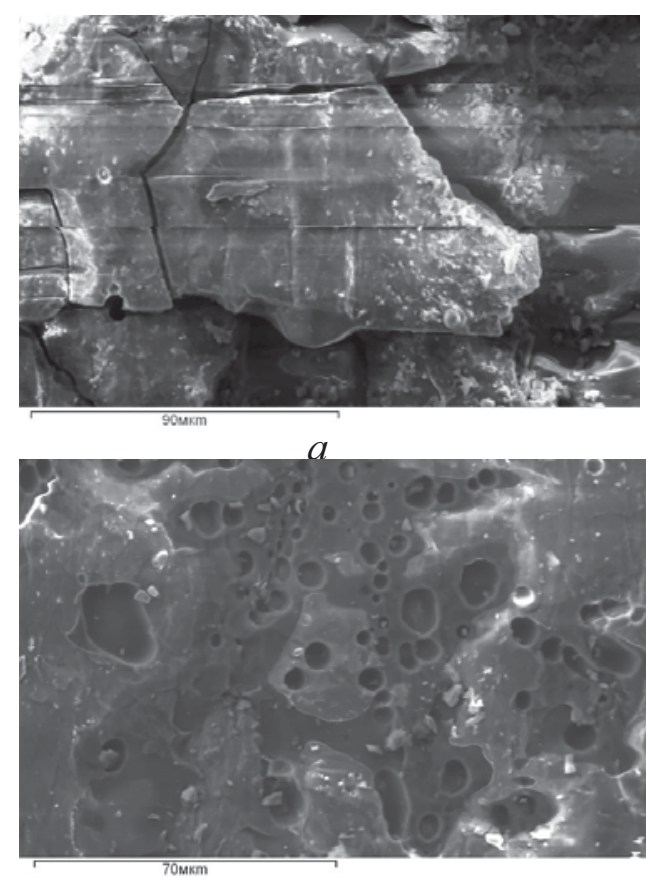

Fig. 3. X-ray microanalysis of the defective zone:

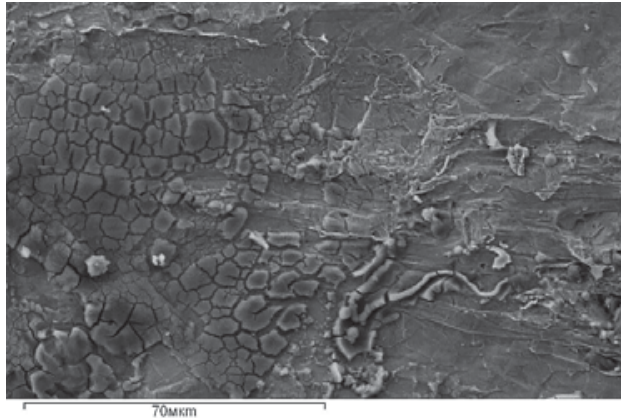

$b$

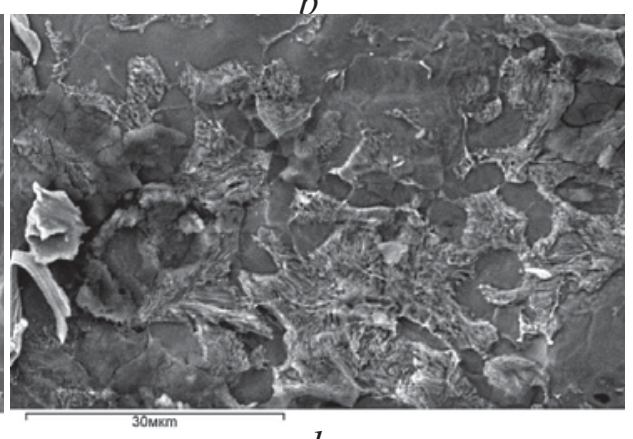

$d$

$a$ - brittle glassy inclusions; $b$-zones with signs of high-temperature impact;

$c$ - inclusions without explicit cracking; $d$ - surface with partially removed bloom

Table 2. Concentration of chemical elements in lamination layers

and pearlite crystal structure with the explicit anisotropy of rolling (fig. 2).

The study has revealed several carbon-free zones around rolled inclusions in some samples; a number of samples demonstrated a layered structure with incorporated ferrite layers (fig. $2 c, d$ ). The structure of rolled inclusions is extended, dot-type and lengthy. Some samples show the grain heterogeneity and different relation of pearlite and ferrite percentages (fig. $2 c, d$ ). The width of inclusions varies in a wide range from $0.1 \mu \mathrm{m}$ to $1 \mathrm{~mm}$. Inclusions are found nearly throughout the entire pipe wall thickness, forming defective zones with the total width up to $5 \mathrm{~mm}$. Besides a distinct stripe-like structure typical for the rolled steel there are layers with irregularly distributed ferrite and pearlite in defect zones of samples. A guideline to evaluate a degree of the strip-like structure and the orientation of microstructures is given in [27], however, they are not considered as an intolerable flaw in pipes, indicating only a manufacturing flow deviation.

\subsection{X-ray microanalysis}

An X-ray microanalysis of defective zones was carried out. The chemical composition of steel and lamination products was determined. The study was also focused on structural differences in defective zones (fig. 3).

Several basic inclusions constitute the chemical composition of sample surfaces in defective zones (Tabl. 2). An analysis of spectra in laminations has disclosed fragments of charge materials, e.g. the presence of fluorine and calcium evidences there is not dissolved fluorite (calcium fluoride, $\mathrm{CaF}_{2}$ in the metal) used as a flux in melting furnaces. Main inclusions are found to be aluminum oxide $\left(\mathrm{Al}_{2} \mathrm{O}_{3}\right)$ and silica glass $\left(\mathrm{SiO}_{2}\right)$,

\begin{tabular}{|c|c|c|c|c|}
\hline \multirow{2}{*}{ Element } & \multicolumn{5}{|c|}{ Weight composition of elements, \% } \\
\cline { 2 - 5 } & $\begin{array}{c}\text { Spectrum 1 } \\
\text { (Fig. 3 a) }\end{array}$ & $\begin{array}{c}\text { Spectrum 2 } \\
\text { (Fig. 3 b) }\end{array}$ & $\begin{array}{c}\text { Spectrum 3 } \\
\text { (Fig. 3 c) }\end{array}$ & $\begin{array}{c}\text { Spectrum 4 } \\
\text { (Fig. 3 d) }\end{array}$ \\
\hline $\mathrm{O}$ & 54.06 & 22.10 & 44.74 & 8.96 \\
\hline $\mathrm{F}$ & 6.20 & 0.32 & - & - \\
\hline $\mathrm{Na}$ & - & 1.12 & - & - \\
\hline $\mathrm{K}$ & 0.24 & - & 0.36 & - \\
\hline $\mathrm{Mg}$ & 1.64 & - & 1.55 & - \\
\hline $\mathrm{Ca}$ & 7.40 & - & 11.99 & - \\
\hline $\mathrm{Al}$ & 5.09 & - & 5.53 & - \\
\hline $\mathrm{Si}$ & 18.57 & 0.24 & 19.52 & 0.42 \\
\hline $\mathrm{Mn}$ & 3.55 & 0.21 & 7.93 & 0.79 \\
\hline $\mathrm{Fe}$ & 0.41 & 65.3 & 6.27 & 81.46 \\
\hline $\mathrm{S}$ & - & - & 0.27 & - \\
\hline $\mathrm{C}$ & balanced & balanced & balanced & balanced \\
\hline
\end{tabular}

which are components of broken bricks used instead of a certain amount of fluorite. The research into the chemical composition spectra has revealed a small amount of complex iron and manganese silicates $\left(n \mathrm{FeO} \times m \mathrm{MnO} \times p \mathrm{SiO}_{2}\right)$. Some laminations contain the rolled slag $\left(\mathrm{FeO}, \mathrm{Fe}_{3} \mathrm{O}_{4}, \mathrm{Fe}_{2} \mathrm{O}_{3}\right)$, formed in shrinkage holes and gas bubbles. An amount of sulphur (S) - the most important element for the dendrite liquation is insignificant and detected in one sample only.

\subsection{Ultrasonic thickness measurement}

Ultrasonic thickness measurements were carried out on defective zones in the cut out samples according to parameters specified in optical microscopic analysis. The defects of interests were formed when rolling, so found parallel to the surface, therefore we used the pulsed-echo technique and introduced an ultrasonic wave perpendicular to the prod- 


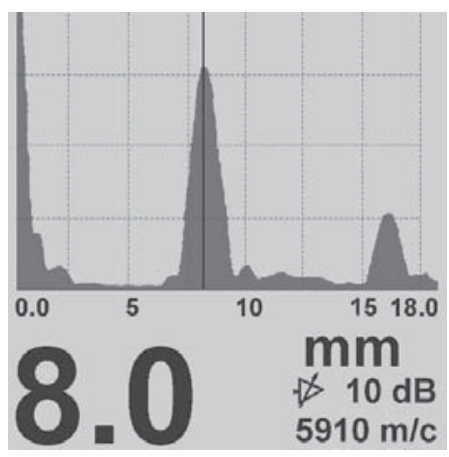

$a$

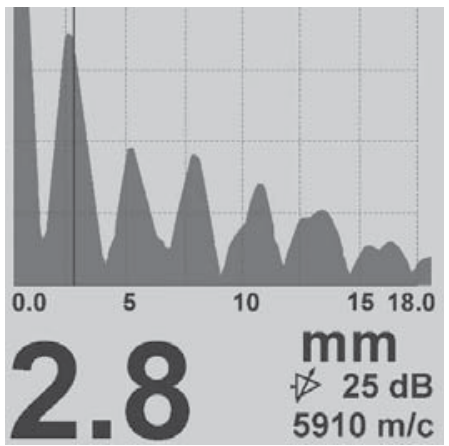

$c$

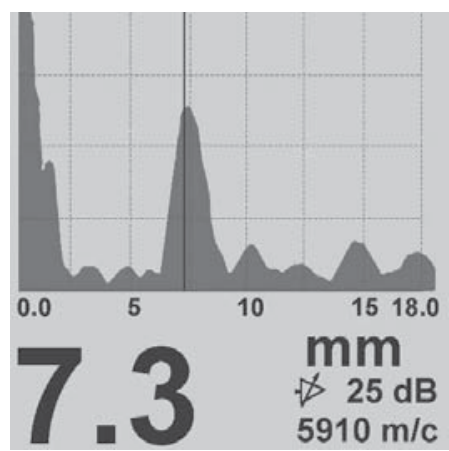

$b$

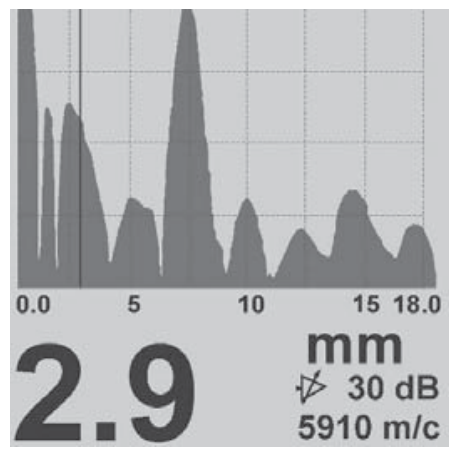

$d$

Fig. 4. Outcomes of ultrasonic measurements:

$a$ - readings recorded on a defect free sample with the thickness of $8 \mathrm{~mm} ; b-$ readings on a pipe wall in a defect free zone; $c$ - readings on the defective zone with the thickness more than $200 \mu \mathrm{m} ; d$ - readings on the defective zone with the thickness less than $100 \mu \mathrm{m}$

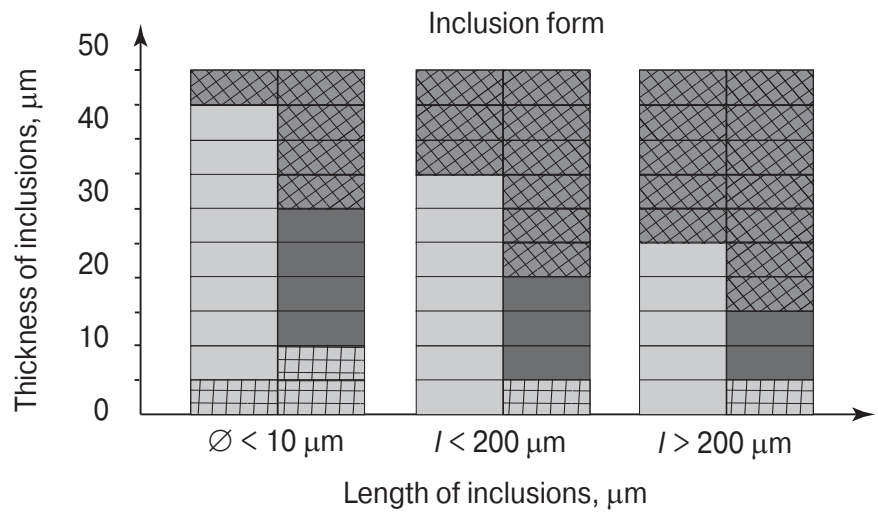

Semi-transparent environment $\square$ Intermediate environment Not transparent environment $\square$ Transparent environment

Fig. 5. Effect of inclusions on the ultrasonic testing results

uct surface. To adjust a thickness measuring device we took standard company samples and vertical flat bottom reflectors with a diameter of $6 \mathrm{~mm}$ as specified in [22]. Two converters with different frequency and emission methods were used. A thickness measuring device was in the mode of amplitude indication of a sample under consideration (A-Scan mode). No serious disagreement between readings was identified, but a single crystal probe $\mathrm{S} 3567$ was more reliable than a double crystal transducer for the less significant effect of sensor orientation on the product.

The ultrasonic measurements carried out on defective zones have revealed a relative dependence of their findings upon thickness of inclusions. As surfaces are not even, the composition and density of dislocations are different, it is hardly possible to determine accurately the exact thickness of inclusions when ultrasonic testing. However, from the measurements carried out on cut out samples it is apparent that separate dot-type and not extended inclusions with the thickness of less than $5 \mu \mathrm{m}$, rolled ferrite stripes and zones displaying a dissimilar pearlite and ferrite structure hardly influence the readings. Inclusions up to $15-20 \mu \mathrm{m}$ form a semi-transparent environment for an ultrasonic wave, which weakens a back wall signal (fig. $4 d$ ), although the signals from several reflective layers are observed on the screen: from a defective area and a bottom wall of a pipe. In most cases these signals are similar to those of liquation zones and zones with partially welded laminations. Extended inclusions thicker than $20 \mu \mathrm{m}$ represent a nontransparent block for an ultrasonic wave (fig. $4 c$ ), so it is not possible to measure the exact thickness of the product.

In light of conducted measurements we detected the regularity and tabulated the data on the relation between thickness and form of extended inclusions and discontinuities on readings of the thickness measuring device (fig. 5).

The readings of measuring devices are instable in the intermediate environment and tend to variations if a measuring device is moved slightly or turned; this phenomenon is observed most frequently when inspecting a material with multi-layered dot-like or extended inclusions.

In laboratory studies samples were examined on both sides. Nevertheless, in real conditions with an access to the object of interest from one side only and "not transparent" inclusions or laminations without a bottom signal it is hardly possible to define whether a defect is not a surface-breaking lamination. An indirect indicator of lamination is suggested to be intermediate and semi-transparent zones on the edge of a defect.

\section{Conclusions}

The research results indicated the insufficient quality of manufactured pipes and various defects within one defective zone in the pipe: shrinkage holes and weakness, gas bubbles and cavities, slag inclusions.

The ultrasonic testing carried out with a large scanning pitch on objects similar to those of interest may fail to detect such defects for their sizes are tiny if taken separately, they are surrounded with zones without or with highly transparent defects. A principal hazard of a laminated zone in a pipe wall giving no bottom signal from the opposite side is the impossibility to determine the precise thickness of a layer with inclusions, thinned zones or defects in a pipe from the 
opposite side. Furthermore, wide layers with inclusions deteriorate the bearing capacity of a product even if the surface is undamaged.

Both current and existed before manufacture and control standards for tubular goods require the ultrasonic testing with the certain increment. Therefore, we can conclude the existence of defect free areas near defective zones and their insignificant extension radially and crosswise is the reason a faulty pipe was ignored at the enterprise. It is necessary to conduct ultrasonic thickness measurements of the output with a smaller scanning pitch to eliminate pipes with such defects on high-duty production sites.

\section{REFERENCES}

1. European gas pipeline incident data group https://www.egig.eu/ startpagina (accessed 20.03.2020).

2. About Gazprom. http://www.gazprom.ru/about/ (accessed 20.03.2020).

3. Harionovskij V.V. Reliability of main natural gas pipelines: rise, development, and present day state. Gazovaya promyshlennost. 2019. No. 1. pp. 56-68.

4. Maruschak P., Danyliuk I., Prentkovskis O., Bishchak R., Pylypenko A., Sorochak A., Degradation of the main gas pipeline material and mechanisms of its fracture. Journal of Civil Engineering and Management. 2014. Vol. 20. pp. 864-872. DOI: 10.3846/13923730.2014.971128.

5. Bolshakov A. M., Syromyatnikova A. S. Degradation of mechanical properties and structure-phase state of pipe metal in main gas lines under long-term operation in Northern regions. Prirodnye resursy Arktiki i Subarktiki. 2018. Vol. 23 (1). pp. 75-80.

6. Hutsaylyuk V., Maruschak P., Konovalenko I., Panin S., Bishchak R., Chausov M., Mechanical properties of gas main steels after long-term operation and peculiarities of their fracture surface morphology. Materials. 2019. Vol. 12 (3). p. 491. DOI: 10.3390/ ma12030491.

7. Marvin C. W. Determining the strength of corroded pipe. Materials protection and Performance. 1972. No. 11. pp. 34-40.

8. Al-Owaisi S. S., Becker A. A., Sun W. Analysis of shape and location effects of closely spaced metal loss defects in pressurised pipes. Engineering Failure Analysis. 2016. Vol. 68. pp. 172-186. DOI: 10.1016/j.engfailanal.2016.04.032.

9. Veliyulin I. I. Determination of allowable parameters in corroded pipes. Territoriya Neftegaz. 2019. No. 11. pp. 40-47.

10. Afanasyev A. V., Melnikov A. A., Konovalov S. V., Vaskov M. I. The analysis of the influence of various factors on the development of stress corrosion defects in the main gas pipeline walls in the conditions of the European part of the Russian Federation. International Journal of Corrosion. 2018. 1258379. DOI: 10.1155/2018/1258379

11. Afanasyev A. V., Melnikov A. A., Savin D. V., Zhukov D. V., Vaskov M. I. A possibility to assess visually the depth of stress-corrosion defects in pipe walls of direct natural gas lines, Polzunovsky vestnik. 2018. No. 4. pp. 170-175. DOI: 10.25712/ASTU.20728921.2018.04.034.
12. Panagopoulos C., Georgiou E., Giannakopoulos K., Orfanos P. Effect of $\mathrm{pH}$ on stress corrosion cracking of $6082 \mathrm{Al}$ alloy. Metals. 2018. No. 8. p. 578. DOI:10.3390/met8080578.

13. Pinheiro B., Pasqualino I., Cunha S. Stress concentration factors of dented pipelines. Proceedings of IPC2006 6th International Pipeline Conference. Calgary. 2006. pp. 335-344. DOI: 1.10.1115/ IPC2006-10598.

14. Palmer-Jones R., Turner S., Hopkins P. A Proposal for the development of an international recommended. Practice in pipeline defect assessment and repair selection. International Conference on The Evaluation and Rehabilitation of Pipelines. Prague. 2008. pp. 1-27.

15. Vilkys T., Rudzinskas V., Prentkovskis O., Tretjakovas J., Višniakov N., Maruschak P. Evaluation of failure pressure for gas pipelines with combined defects. Metals. 2018. No. 8. p. 346. DOI:10.3390/ met8050346.

16. Zhukov D., Konovalov S., Afanasyev A. Morphology and development dynamics of rolled steel products manufacturing defects during long-term operation in main gas pipelines, Engineering Failure Analysis. 2020. Vol. 109. DOI: 10.1016/j.engfailanal.2019.104359.

17. Golikov I. N. Dendrite liquation in steel. M., Metallurgiya. 1958. $206 \mathrm{p}$.

18. Lesoult G. Macrosegregation in steel strands and ingots: characterization, formation and consequences. Mater. Sci. Eng. A. 2005. 413-414, pp. 19-29. DOI: 10.1016/j.msea.2005.08.203.

19. Wu M., Könözsy L., Ludwig A., Schützenhöfer W., Tanzer R. On the formation of macrosegregations in steel ingot castings. Steel Res. Int. 2008. Vol. 79 (8). pp. 637-644. DOI: 10.1002/ srin. 200806177.

20. GOST 19200-80. Iron and steel castings. Terms and definitions of defects. http://docs.cntd.ru/document/gost-19200-80 (access date 14.09.2020).

21. GOST 31447-2012. Steel welded pipes for trunk gas pipelines, oil pipelines and oil products pipelines. Specifications. http://docs. cntd.ru/document/1200103347 (access date 14.09.2020).

22. GOST R ISO 10893-9-2016. Seamless and welded steel tubes. Part 9. Automated ultrasonic testing for the detection of laminar imperfections in strip/plate used for the manufacture of welded steel tubes. http://docs.cntd.ru/document/1200133102 (access date 14.09.2020).

23. GOST R ISO 10893-8-2017. Seamless and welded steel tubes. Part 8. Automated ultrasonic method of testing for the detection of imperfections. http://docs.cntd.ru/document/1200157819 (access date 14.09.2020).

24. GOST 31447-2012. Steel welded pipes for main gas, oil and oil products pipelines. Technical conditions http://docs.cntd.ru/ document/1200103347 (access date 27.02.2020).

25 . GOST 1050-88. Graded and sized rolled metal with specially machined surface manufactured from quality constructional steel. General technical conditions (with revisions N 1, 2) http://docs. cntd.ru/document/1200004986 (access date 27.02.2020).

26. Failure analysis of heat treated steel components, ASM International, 2008, $640 \mathrm{p}$.

27. GOST R 54570-2011. Steel. Assessing the degree of banding or orientation of microstructures. http://docs.cntd.ru/document/1200093206 (access date 14.09.2020). 